\title{
DESFIANDO FIOS RETORCIDOS DE UMA LONGA HISTÓRIA: ENCONTROS COM A LITERATURA DE CONCEIÇÃO EVARISTO
}

Unraveling twisted wires from a long story: meetings with Conceição Evaristo's literature

\author{
Andréa Figueiredo Leão Grants \\ D https://orcid.org/0000-0001-6533-3365 \\ Bianca Rosina Mattia \\ D https://orcid.org/0000-0002-0136-1241 \\ Daniela Stoll \\ https://orcid.org/0000-0001-8843-779X \\ Elton da Silva Rodrigues \\ (iD) https://orcid.org/0000-0002-1890-7482 \\ Isabele Soares Parente \\ (iD https://orcid.org/0000-0003-0561-5488 \\ Jair Zandoná \\ https://orcid.org/0000-0002-4301-9436 \\ Marina Siqueira Drey \\ (iD) https://orcid.org/0000-0002-6894-5567

\section{Tânia Regina Oliveira Ramos} \\ iD http://orcid.org/0000-0002-2477-0419
}

Universidade Federal de Santa Catarina, Programa de Pós-Graduação em Literatura,

Florianópolis, SC, Brasil, 88040-900

A primeira edição de 2019 da revista Anuário de Literatura apresenta à comunidade de leitoras e leitores o dossiê intitulado Representações afro-brasileiras: uma homenagem a Conceição Evaristo. Esta deferência, assim como a que a escola de samba Acadêmicos da Abolição prestou recentemente à escritora, também ressoa o belíssimo samba-enredo "A escrevivência abolicionista em versos, poemas e contos". O dossiê que ora apresentamos reafirma o quanto Conceição Evaristo, em sua obra, questiona as opressões vividas pela 
população negra ao mesmo tempo em que resgata a força da ancestralidade afro-brasileira e, assim como sua personagem Ponciá Vicêncio, vai desfiando "fios retorcidos de uma longa história." (EVARISTO, 2017, p. 110).

Opondo-se a uma situação que legitima a possibilidade de apenas determinados segmentos usufruírem dos direitos à livre expressão do pensamento e à criatividade e que a outros grupos estatui dificuldades ao efetivo exercício desses mesmos direitos, as vozes presentes na escrita de Conceição Evaristo ecoam memórias coletivas de dor, de sofrimento, mas também de amor, de união e da possibilidade do livre pensamento, da criatividade e da liberdade. Com isso, a capa da atual edição, elaborada a partir de uma fotografia de Fernando Lusvarghi e editada por Ricardo Henrique Wiggers, apresenta uma criança negra que corre de braços abertos avançando destemidamente o caminho a sua frente. $\mathrm{O}$ efeito de desfragmentação utilizado na imagem transforma partes que se desprendem do corpo da menina em borboletas, folhas e andorinhas, e procura simbolizar o direito à liberdade criativa que a escrita de mulheres negras busca legitimar. Afinal, "As andorinhas têm os seus mistérios”, escreveu oportunamente Paulina Chiziane (2017, p. 53), quando da presença dessas aves e a liberdade que seu voo pode representar.

Os artigos aqui presentes partem da obra de Conceição Evaristo ou de produções literárias que dialogam com os temas trabalhados pela autora, como os movimentos de resistência negra no Brasil e o resgate da ancestralidade afro-brasileira. Organizados a partir dos gêneros discursivos, os estudos investigam poemas, contos e um romance da escritora mineira, cuja escrita se constitui concomitantemente como testemunho, ficção e um projeto político e social fundamental no Brasil contemporâneo, além da produção literária de outros autores na qual se estabelece um diálogo entre os temas abordados na obra de Conceição Evaristo.

Em Memória rastro em poemas de Conceição Evaristo, artigo que abre a edição, Rosana Arruda de Souza analisa a produção poética evaristiana assinalando o desvelamento da voz negra feminina realizado na obra da autora. Considerando a memória de vozes negras como construtoras dos rastros da poesia de Conceição Evaristo, a autora discute como essa mesma poesia potencializa tais vozes a partir do conceito derridiano de rastro num diálogo com o conceito de memória. O rastro, como o concebe Derrida (1973, p. 75), "não é somente a desaparição da origem, ele quer dizer que a origem não desapareceu sequer, que ela jamais foi retroconstruída, a não ser por uma não-origem, o rastro, que se torna, assim, origem da origem.”, de modo a apontar o que existe, mas que esteve sempre à margem.

$\mathrm{Na}$ sequência, Henrique Marques Samyn, em Para (re)ler "Vozes-mulheres" Conceição Evaristo e a dialética da ancestralidade, apresenta uma profícua leitura sobre o poema "Vozes-mulheres". O estudo se propõe a analisar profundamente os elementos retóricos, formais e rítmicos que constituem o poema, bem como seu processo dialético, protagonizado exclusivamente por figuras femininas, e a determinação da liberdade dessas mulheres.

A seguir, o artigo Leitura e análise semiótica do poema/canção "Eu-mulher": a poesia em canto e dança, de Jaquelânia Aristides Pereira e Maria de Fátima Vasconcelos da Costa, explora o fazer poético de Conceição Evaristo. A análise semiótica das autoras, elaborada à luz 
dos estudos de Tatit (2005), busca relacionar o poema "Eu-mulher" com o feminismo sagrado e o feminismo negro, além de observar a recriação musical e de danças realizadas pelo compositor Renato Gama e pela dançarina Malu Avelar, investigando a potencialidade comunicativa da recriação correlacionada aos sentidos do poema.

Em Dona Maria Baia: uma escritora de si, José Luiz da Silva Lima e Jailma dos Santos Pedreira procuram mostrar como a produção artística de Maria José Dantas das Mercês, Dona Maria Baia, ajudou a produzir outras subjetividades para si e para outras mulheres, interferindo no coletivo comunitário, de modo a desencadear outros modos de vida e outra percepção de si, que se desenha como resistência ao patriarcado e às condições de subalternidade. Para argumentar sobre a resistência às condições de subalternidade, os autores dialogam com o crítico cultural Osmar Pereira Santos (2016) em sua fala acerca da luta dos subalternos:

[...] e seus modos de enunciação são singulares e respondem a uma dobra do poder, como acontecimento: confronta o chefe local, expõe representantes do sistema de poder (a cada instância que interpela e supera em sua vontade de justiça), mobiliza seus parcos recursos de camponeses pobres... [...] ativa sua sensibilidade e inteligência, à medida em que os desafios vão se colocando durante seu processo de luta e enfrentamento (SANTOS, 2016, p. 61).

Iniciando a sequência de artigos na qual se realiza a análise de contos de Conceição Evaristo, Thaizy Cristhine Salles Bento e Emerson da Cruz Inácio, em "Havia um segredo que só Halima sabia": confluências entre literatura afro-brasileira e mitologia dos Orixás, visam notabilizar o movimento confluente entre as narrativas mítico-religiosas e ancestrais africanas e afro-brasileiras e a produção literária afro-brasileira, intuindo não apenas assinalar as semelhanças e identificar possíveis fontes, mas também propor caminhos interpretativos.

Em La poética de la negritud femenina en "Ana Davenga" ¿Revelación de una necroescritura?, Rafaela Cassia Procknov se propõe a investigar como diversas questões sociais que afetam a população afrodescendente brasileira são elaboradas a partir da poética feminina do conto "Ana Davenga". Para tanto, a autora se utiliza de um arcabouço teórico que leva em consideração as abordagens de Achille Mbembe, Giorgio Agamben, Jacques Lacan, Judith Butler e Riviera Garza.

Camila Savegnago e Vera Lucia Lenz Vianna tecem algumas considerações sobre as temáticas da identidade, alteridade e civilidade a partir da leitura do conto "Maria", de Conceição Evaristo. Em seu trabalho, Maria maldita: a falência da civilidade em "Maria", de Conceição Evaristo, as autoras também refletem sobre a questão da alteridade na sociedade contemporânea, o esvaziamento de civilidade e, por conseguinte, a promoção de hostilidade nas relações entre indivíduos.

A seguir, há dois artigos cujas análises são construídas a partir do conto "Isaltina Campo Belo”. Em Imaginários sociodiscursivos da mulher negra: análise do conto Isaltina Campo Belo, de Conceição Evaristo, Avanete Pereira Sousa e Emanuela de Souza Cordeiro, com base no arcabouço teórico da Semiolinguística, do linguista francês Patrick Charaudeau, apresentam uma análise discursiva do conto. Geny Ferreira Guimarães e Hildalia Fernandes Cunha 
Cordeiro, por sua vez, em Campo Belo: narrativa insubmissa e insurgente, problematizam os silêncios impostos historicamente sobre a sexualidade da mulher negra, observando a forma como esses silêncios são constituídos, propondo a insurgência e a insubmissão como categorias existenciais e chaves interpretativas para a análise do conto.

Em Morrer de pé para não viver de joelhos: o suicídio de Bertoleza em $\boldsymbol{O}$ cortiço, de Aluísio Azevedo, artigo que dá início às análises de romances, Emanuel Régis Gomes Gonçalves analisa o suicídio de Bertoleza, mostrando como o ato dessa personagem conjugase com formas de insubmissão e resistência encontradas pelos negros e negras no Brasil antes da Abolição.

Ariane Avila Neto de Farias e Lilian Greice dos Santos Ortiz da Silveira, em O espaço que somos: as relações entre a favela e a construção da subjetividade em Becos da memória, de Conceição Evaristo, analisam aspectos referentes ao espaço neste romance evaristiano. Para as autoras, a voz no "espaço-favela" possibilita um movimento de descentralização que dá visibilidade às diferenças, uma vez que, como pontuam, "dar corpo à memória dos moradores da favela, caminhando em memória em sentido contrário ao dos estereótipos que se colam à pele dos subalternos em nossa sociedade, é, portanto, uma estratégia de grande impacto político e cultural" (SCHMIDT, 2017, p. 186).

No artigo que finaliza este número, Legacies and memories of violence in Becos da memória/Legado e memórias da violência em Becos da memória, Leila Lehnen reflete sobre como o conceito de "violência lenta" (slow violence) (NIXON, 2011) estrutura a narrativa do romance, observando como essa espécie de violência influencia a vida cotidiana de populações pobres e racializadas.

A finalizar esta reflexão introdutória, agradecemos imensamente a todas as autoras e a todos os autores que compõem este número, especialmente pelo empenho, pela dedicação e pela participação. Nosso agradecimento também se volta à Equipe do Portal de Periódicos da Biblioteca Universitária da UFSC pelo suporte e apoio para mais esta publicação. Como periódico acadêmico que é pensado e construído em uma instituição superior de ensino público e que abriga pesquisas de outras tantas instituições públicas, do Brasil e também de outros países, às quais se vinculam muitas/os pesquisadoras e pesquisadores, sejam professoras, professores, alunas ou alunos, e considerando os ataques que a educação pública vem sofrendo, a publicação deste número é também um grifo de nossa resistência nesses tempos difíceis. Com isso, pedimos a todas e a todos que por aqui passarem que não deixem de divulgar a Anuário de Literatura, unindo-se, assim, a uma luta que é nossa, a uma luta, sobretudo, pela educação pública no Brasil.

Desejamos a todas e a todos boas leituras!

\section{Referências}

DERRIDA, Jacques. Gramatologia. Trad. de Miriam Chnaiderman e Renato Janine Ribeiro. São Paulo: Perspectiva: USP, 1973.

CHIZIANE, Paulina. As andorinhas. Belo: Horizonte, Nandyala, 2017. 
EVARISTO, Conceição. Ponciá Vicêncio. 3. ed. Rio de Janeiro: Pallas, 2017.

NIXON, Rob. Slow violence and the environmentalism of the poor. Cambridge, Mass.: Harvard University Press, 2011.

SANTOS, Osmar Moreira dos. A luta desarmada dos subalternos. Belo Horizonte: UFMG, 2016.

SCHMIDT, Simone Pereira. Posfácio: a força das palavras, da memória e da narrativa. In: EVARISTO, Conceição. Becos da memória. Rio de Janeiro: Pallas, 2017, p. 185-190.

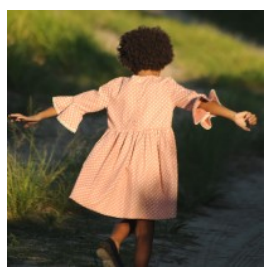

